\title{
Selective inhibition of hemeoxygenase-1 as a novel therapeutic target for anticancer treatment
}

\author{
Babasaheb Yadav ${ }^{1}$ and Khaled Greish ${ }^{1,2 *}$
}

${ }^{1}$ Department of Pharmacology \& Toxicology, Otago School of Medical Sciences, University of Otago, Dunedin, New Zealand ${ }^{2}$ Department of Oncology, Suez Canal University, Ismailia, Egypt

\begin{abstract}
Effective and safe anticancer treatment remains a challenge to the scientific community. Major disadvantage inherent to current anticancer strategies is their lack of targeting tumour cells, or tissues resulting in sever dose limiting toxicity. Researches in the field of anticancer drug delivery are currently exploring the potentials of nanotechnology to realize the "magic bullet" professed by Paul Ehrlich at the turn of the $20^{\text {th }}$ century. Heme oxygenas-1 (HO-1) is over expressed as a survival factor in tumour tissues to withstand adverse tumour micro environmental factors such as hypoxia, hypoglycaemia, and significant acidity. Inhibition of HO-1 activity thus can be a viable anticancer strategy. However HO-1 is essential for multiple physiological and adaptive responses in normal tissues of different organ systems. Utilizing nanotechnology advancement to selectively inhibit HO-1 activity in tumour tissue is being currently explored as a novel strategy for effective anticancer management. In this review we discuss the function of HO-1 in physiological conditions, its role in cancer progression and the potential therapeutic implication for selective inhibition of $\mathrm{HO}-1$ in tumour tissues.
\end{abstract}

\section{The physiology of hemeoxygenase, its isoenzymes and tissue of origin}

Heme oxygenases are the rate limiting enzymes that catalyze the metabolism of heme into equimolar concentrations of carbon monoxide (CO), free iron and the bile pigment biliverdin. Biliverdin is further converted to bilirubin by bilirubin reductase [1,2]. CO, the product of heme degradation acts as a physiological stimulator of soluble guanylate cyclase (sGC) and regulates neuronal, vasodilatory and inflammatory signaling [3]. The functional role of $\mathrm{CO}$ was verified by using Zinc protoporphyrin ( $\mathrm{ZnPP})$, the competitive inhibitor of HO-1, which acts by inhibiting soluble guanylate cyclase (sGC) [4].

In humans there are three active isoforms of heme oxygenase namely, HO-1, HO-2 [1,5] with $\mathrm{HO}-3$, the least active isoenzyme having 90\% homology with HO-2 [6]. Both HO-1 and HO-2 isoenzymes are products of two distinct genes and share approximately $40 \%$ amino acid homology [7]. HO- 1 is a $32 \mathrm{kDa}$ protein also known as heat shock protein-32 (Hsp32) which was first purified from rat liver [8]. Subsequently, it was also identified in humans [9] and was found to be constitutively expressed in human renal inner medullary cells [10], Kupffer cells in the liver [11], purkinje cells in the cerebellum [12] and CD4+/CD25+ regulatory T lymphocytes [13] under normal physiological conditions. This wide range of expression of HO-1 in different organs was a clue of its important role for different organ functions. The expression of HO-1 can also be induced by variety of stimuli such as its own substrate heme, reactive oxygen species (ROS), hydrogen peroxide, heavy metals, hypoxia, NO, ultraviolet radiation, prostaglandins, cytokines, growth factors like insulin and lipopolysaccharide and certain therapeutic agents such as nonsteroidal anti-inflammatory drugs, antidiabetic thiazolidinediones and statins [14-18]. HO-2 is a $36 \mathrm{kDa}$ protein which is found to be expressed in testis, brain, endothelium, distal nephron segment, liver and gut myenteric plexus [1,2]. The biological functions of HO-1 are mainly associated with a basic adaptive and defensive response against oxidative and cellular stress and to maintain cellular homeostasis $[19,20]$. Numerous cell signaling pathways including extracellular signal-regulated kinases ERK1 and ERK2, c-jun-NH2-kinase (JNK) and $\mathrm{p} 38$ kinase, protein kinase $\mathrm{C}$ (PKC), phosphoinositol and protein kinase A mediate the transcription of $\mathrm{HO}-1$, which ultimately regulates cell survival and offers cytoprotection [21]. The central role of HO-1 in protection against oxidative stresses was demonstrated in $\mathrm{HO}-1$ knockout mice [22] and also in a patient with an inherited HO-1 deficiency [23] where results showed a reduction in the protective responses against oxidant stress (Figure 1)

$\mathrm{CO}$ generated during heme catabolism assists in cytoprotective effects via anti-inflammatory, anti-proliferative and antiapoptotic activity [21]. Cross talk exists between HO system and NOS system [24]. It is evident that the $\mathrm{NO} / \mathrm{NOS}$ system induces $\mathrm{CO} / \mathrm{HO}$ system while $\mathrm{CO} / \mathrm{HO}$ system reciprocately regulates the $\mathrm{NO} / \mathrm{NOS}$ system [25]. HO can regulate the production of $\mathrm{NO}$ via multiple mechanisms (Maines, 1997). NO/HO-1 system has been shown to produce protumoral effects through decrease cell growth inhibition and induction of cell survival [26].

Prelude to the protective effect of HO-1 in cancer cells were the various preclinical and clinical studies demonstrating a protective role of HO-1 in cardiovascular, renal disease and ischemia perfusion injury. Wang et al. [27] reported that sustained HO-1 upregulation in the failing heart serves to mitigate detrimental left ventricular (LV) remodeling via antioxidant, antihypertrophic, antifibrotic, and proangiogenic effects in mice [27]. Moreover, a clinical study in patients with peripheral artery disease showed that HO-1 genotype exerts protective effects against adverse coronary events [28]. Similarly, $\mathrm{HO}$ induction exerts a protective effect on renal function in animal models of rhabdomyolysis, cisplatin nephrotoxicity and nephrotoxic

*Corresponding author: Khaled Greish, Adams building, 18 Frederick street, level 2 room 238, Tel: + 64- 3- 479- 4095; Fax: +64 -3-479-9140; E-mail: khaled. greish@otago.ac.nz

Received September 15, 2011; Accepted November 08, 2011; Published November 12, 2011

Citation: Yadav B, Greish K (2011) Selective inhibition of hemeoxygenase-1 as a novel therapeutic target for anticancer treatment. J Nanomedic Nanotechnol S4:005. doi:10.4172/2157-7439.S4-005

Copyright: () 2011 Yadav B, et al. This is an open-access article distributed under the terms of the Creative Commons Attribution License, which permits unrestricted use, distribution, and reproduction in any medium, provided the original author and source are credited. 


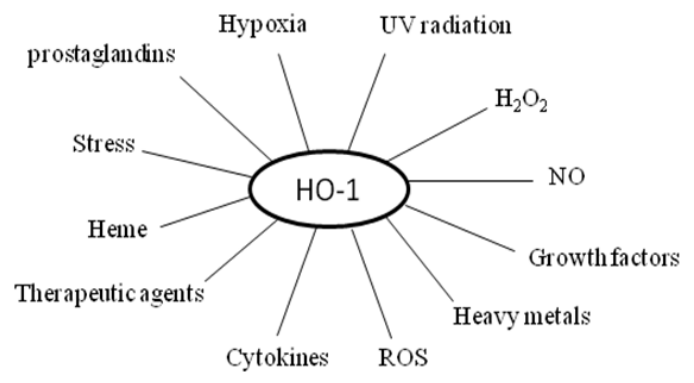

Figure1: Factors involved in $\mathrm{HO}-1$ expression in various tissues.

nephritis [29]. Furthermore, HO-1 derived $\mathrm{CO}$ provided protective effects in acute kidney injury and hypertension. In addition, $\mathrm{HO}-1$ derived $\mathrm{CO}$ increased blood carboxyhoemoglobin levels, renal blood flow and glomerular filtration [30]. In vivo expression of $\mathrm{HO}-1$ protects kidneys from acute ischemic failure or ischemia/reperfusion injury [31] and cardiac xenografts from rejection [32]. Also, exposure of kidney graft recipients to low concentrations of HO-1 derived $\mathrm{CO}$ imparted significant protective effects against renal $I / R$ injury and improve function of renal grafts [33]. The wealth of these studies warranted the evaluation of the role of HO-1 in solid tumors.

\section{Role of HO-1 in tumor progression and tumor maintenance}

While the HO-1 mediated cyto-protective effect plays an essential role in adaptive protection of different organs against oxidative stress, it can also shift the endogenous balance between apoptosis and proliferation towards an anti-apoptotic and anti-proliferative status, thereby promoting cancer formation and maintenance. HO-1 over expression was demonstrated in various cancer cells compared to surrounding healthy tissue leading to an increased survival of neoplastic cells [34]. In addition, HO-1 gene polymorphism was associated with an increased chance of cancer development [35].

HO-1 is over expressed in various tumor tissues derived from all the three germ layers such as brain tumors, lung cancer, hepatoma, colon carcinoma and prostate carcinoma [36-41]. HO-1 was induced in cancer cells by different stimuli. For example, in Kaposi sarcomas, HO-1 is induced by a Kaposi sarcoma-associated herpes virus (KSHV) [42] and in chronic myeloid leukemia and mast cell neoplasm it was induced by oncogenes BCR/ABL fusion kinase [43] and KIT D816V [44], respectively. Moreover, HO-1 was induced by NO in AH136B hepatoma [45] and by hemin and cadmium in human gastric cancer cells [46]. Finally, HO-1 can also be induced in cancer cells in response to chemotherapy, irradiation or photodynamic therapy [47-49]. The inherent over expression either in response to tumor microenvironment or in response to suboptimal anticancer therapy can thus provide a valuable therapeutic opportunity for treatment to both primary as well as refractory tumors (Figure 2).

Although, exact mechanism by which HO-1 causes increased proliferation and survival of cancerous cells is uncertain, some of the widely reported processes include, antiapoptotic effects, altered expression of cell cycle and promotion of angiogenesis [19,34]. HO-1 effect on the cell cycle is mainly mediated through the cell cycle regulatory protein, $\mathrm{p} 21$. HO- 1 activation reduces the expression of $\mathrm{p} 21$ in endothelial cells, melanoma and colon carcinoma [50,34]. However, p21 expression was found to be up regulated in thyroid carcinoma [51] and gastric cancer [46].
The antiapoptotic effects of HO-1 have been documented in various cancer cells. HO-1 blocks apoptosis by three major pathways, namely, decreased intracellular pro-oxidant level, increased bilirubin level and elevated CO production [19]. Lin et al. [52] demonstrated that nuclear localization of HO-1 is an important signaling event in cancer cells which may up regulate genes that provide cytoprotection from oxidative stress [52]. In rat $\mathrm{AH} 136 \mathrm{~B}$ hepatoma cells, $\mathrm{HO}-1$ exerted anti-apoptotic effects against oxidative stress induced by NO [45] In melanoma cells, HO-1 overexpression caused resistance against oxidative stress and consequently leads to tumor growth in vivo [34]. The cytoprotective role of HO-1 has been shown to be dependent on p38 MAPK and PI3K/Akt signal transduction pathway which further modulate the expression of apoptosis related genes [5]. Specifically, antiapoptotic effects of HO-1 in gastric cancer cells are independent of p53 status in a p38 MAPK and ERK mediated pathway and show elevated caspase inhibitory protein2 (c-IAP2) and decreased caspase 3 activity [46]. In addition, the increased activity of HO-1 was associated with increased nuclear localization of NFKB. The antiapoptotic effect of HO-1 was also reported in thyroid cancer cells [51]. This effect was mediated via activation of a p38 MAPK and ERK. Moreover, Busserolles et al. [50] reported that $\mathrm{HO}-1$ produced resistance to apoptosis in colon cancer cells by modification of the Bcl-2/Bax ratio towards survival [50]. This effect was independent of $\mathrm{p} 38$ but mediated via the Akt pathway. In bladder cancer, HO-1 induced by hypericinphotodynamic therapy required functional p38 MAPK and PI3K pathways to confer a cytoprotective effect, probably through the control of the nuclear availability of the Nrf2 pool [48]. Furthermore, Banerjee et al. [53] reported the role of the Ras-Raf-ERK pathway that activates the expression of HO-1 in human renal cancer cells [53]. This further mediates anti-apoptotic signal leading to cancer cell survival. The cytoprotective action of HO-1 was also enhanced by supplementation of cultured cells with biliverdin or bilirubin as shown in hepatoma and colon carcinoma cells $[45,50]$. However, HO-1 derived CO was unable to provide cytoprotection in colon carcinoma, gastric cancer cells and chronic myelogenous leukemia $[43,50]$

Koiso et al. [54] reported the role of HO-1 in the modification of differentiation of human myeloid leukemia cells (K562) [54]. Similarly, Wang et al. [55] reported the association of high expression of HO-1 and tumor differentiation in gall bladder cancer [55]. Further, Mayerhofer et al. [56] reported that HO-1 is involved in BCR/ABLdependent survival of CML cells [43]

Another mechanism by which HO-1 leads to cancer cell survival is by offering resistance to anticancer treatment as shown in pancreatic cancer [47], colon cancer, lung carcinoma [39] and chronic myeloid leukemia $[43,56]$. The enhanced sensitivity of cancer cells towards radiotherapy and chemotherapy was further explored by therapeutic inhibition of HO-1 in these cells.

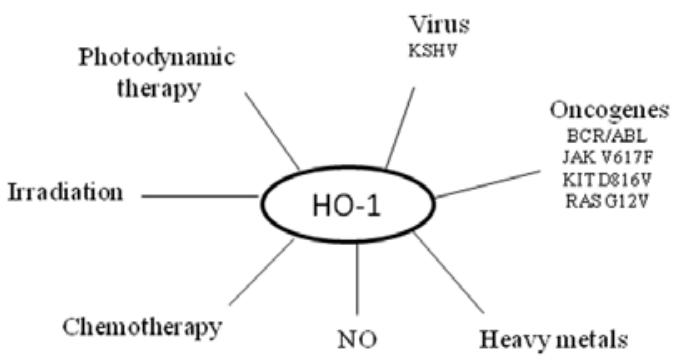

Figure 2: Factors activating $\mathrm{HO}-1$ expression in tumors. 
HO-1 may also play a role in tumorigenesis by reducing antitumor immunity and anticancer immunotherapy. It is established that HO-1 exerts $\mathrm{T}$ cell immune suppression thereby generating induced $\mathrm{T}$ regulatory cell (Treg) activities and helping cancer cells to escape immune response [57]. Importantly, HO-1-specific CD8+T cells were detected ex vivo and in situ among $\mathrm{T}$ lymphocytes from malignant melanoma, renal cell carcinoma and breast cancer patients which effectively suppressed cell immune responses [58]. HO-1 specific T cells isolated from the peripheral blood of cancer patients inhibited cytokine release, proliferation and cytotoxicity of other immune cells.

Recently, Tauber et al. [59] carried out gene expression profiling of HO-1 and reported its association with tumorigenesis. They demonstrated that the protein network downstream of HO-1 modulates adhesion, signaling, transport, and other critical cellular functions of neoplastic cells and therefore promotes tumor cell growth and dissemination [59]. The role of HO-1 gene promoter polymorphism is studied in various cancer patients and its association with cancer development is established. For example, Vashist et al. [60] evaluated the prognostic value of the transcription controlling GTn repeat germ line polymorphism in the promoter region of the HO-1 gene in curatively resectable pancreatic cancer patients. They found that the short GTn allele (SGTn) was associated with aggressive biological tumor behavior. Furthermore, SGTn had the worst disease-free and overall survival. They also reported a steadily increasing risk between LL, SL, and SS genotype patients for larger tumor size, presence of lymph node metastasis, poor tumor differentiation and higher recurrence rate [60]. Similarly in urothelial cancers, constitutive expressions of HO-1 were associated with the presence of SGTn [61]. Some studies have also reported the association of higher frequency of long GTn allele (LGTn) and greater risk of cancer as shown in patients with oral squamous cell carcinoma [62], lung adenocarcinoma [35], esophageal squamous cell carcinoma [63], breast cancer [64] and gastric adenocarcinoma [65].

\section{Role of HO-1 in angiogenesis and metastasis}

Tumor progression beyond $2 \mathrm{~mm}$ is totally dependent on efficient blood supply [66]. Further access of tumor cells to functional blood vessels is a prerequisite for its metastasis to distant organs. Angiogenesis is the process of formation of new blood vessels which supply nutrients for growing tumors. Tumor angiogenesis thus, is essential for the development and metastasis of tumors [66]. HO-1 has shown proangiogenic potential in addition to the cytoprotective effects. It was reported that genetic over expression of $\mathrm{HO}-1$ in endothelial cells increased production of VEGF and consequently produced endothelial cell proliferation, migration and formation of capillarylike tube structure [67]. Soares et al. [32] first demonstrated that the overexpression of HO-1 prevents apoptosis in endothelial cells [32]. This anti-apoptotic effect was mediated via degradation of p38a MAPK isoform [68].

HO-1 promotes endothelial cell proliferation and tumour vascularization in various types of cancers [69]. For example, expression of HO-1 increases the angiogenic potential of murine melanoma resulting into increased tumor vascularization [34]. In human gliomas and vertical growth melanomas, HO-1 expression was observed in infiltrating macrophages leading to increased vascular density and tumor vascularization [12,70]. Furthermore, in melanoma and oligodendroglioma, expression levels of HO-1 in macrophages correlated with tumor cell invasiveness and poor prognosis $[36,70]$. HO-1 stimulated in vitro tumor angiogenesis and increased endothelial cell survival in pancreatic carcinoma [69]. Recently, Miyake et al. [61] demonstrated that overexpression of HO-1 promotes angiogenesis in urothelial carcinoma cells [71]. In addition, inhibition of HO-1 in vivo decreased tumor growth and micro vessel density (MVD) by suppressing angiogenic factors, particularly HIF- $1 \alpha$ and subsequently VEGF. Furthermore, the principal role of HO-1 in angiogenesis was confirmed through administration of HO-1 inhibitor or siRNA which showed decreased VEGF expression and cell survival as shown in endothelioma, hepatocellular carcinoma, lung carcinoma and in tumors formed by transformed fibroblasts [72,42,73,41]

As angiogenesis further leads to the metastasis, the effect of HO-1 expression on metastasis has also been studied. Was et al. [34] reported that expression of HO-1 in melanoma cells leads to the increased number of metastasis in lung which further shortened the survival of mice [34]. Similarly, pancreatic cancer cells over expressing HO-1 produced increased lung metastasis in mice [69]. In prostate carcinoma, silencing of the HO-1 gene reduced cell invasion in vitro and inhibited growth of primary and metastatic tumors in vivo [74]. Recently, Chong et al. [75] reported that overexpression of HO-1 can enhance tumor metastatic ability through cell invasiveness in patients with NSCLC [75].

However, the ability of HO-1 to produce metastatic effects remains controversial. For example, endogenous HO-1 inhibits migration and the invasive capacity of certain prostate cancer cells [76]. Furthermore, in MCF-7 breast cancer cells, HO-1 inhibited invasion induced by TPA [77]. Also, colorectal cancer patients expressing HO-1 showed lower rate of lymphatic tumor invasion and fewer lymph node metastases [78] and in oral carcinoma, $\mathrm{HO}-1$ was suggested as a marker of low risk of metastasis. These data suggests that the role of HO-1 in metastasis is cell specific and in some cases it can paradoxically reduce the metastatic ability of cancer cells (Figure 3 ).

\section{Therapeutic implication of HO-1 inhibition}

Numerous studies have reported the therapeutic implications of HO-1 in various solid tumors. Berberat et al. [47] reported higher expression of HO-1 in human pancreatic tumors [47]. The targeted knockdown of HO-1 expression led to pronounced growth inhibition of the pancreatic cancer cells and increased sensitivity towards radiotherapy and chemotherapy [47]. Similarly, Sunamura et al. [69] demonstrated that HO-1 over expression leads to pancreatic cancer aggressiveness, by increasing tumor growth, angiogenesis and metastasis. The inhibition of HO-1 expression significantly decreased the tumor growth and lung metastasis in SCID mice inoculated with Panc-1/hHO-1 cells [69]. These studies show that administration of HO-1 inhibitors might be effective for the treatment of pancreatic cancers.

HO-1upregulation was also reported in human hepatocellular carcinoma cells (HCC) where it was associated with poor prognosis

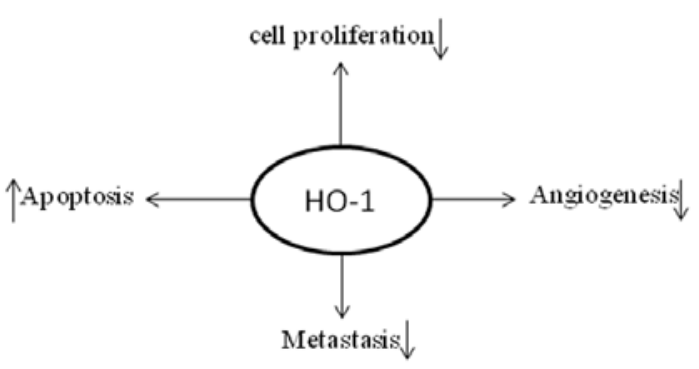

Figure 3: Possible antitumor mechanisms of $\mathrm{HO}-1$ inhibition in tumors. 
due to its protective and anti-apoptotic activity [41]. Down regulation of HO-1 resulted in cytotoxic effects in hepatoma cells both in vitro and in vivo $[37,45]$. Over expression of HO-1 contributes to tumor radioresistance in HCC and indicates the potential therapeutic benefits of HO-1 inhibition in tumor tissues prior to hepatic irradiation [79].

Hill et al. [80] reported the higher expression of HO-1 in human breast cancer cells [80]. They showed that HO-1 inhibited human breast cancer cell proliferation. This study reported for the first time the anti-tumor activity of HO-1 in breast cancer cells and was contradictory to the anti-apoptotic effects of HO-1 in other types of cancers. In addition, HO-1 also inhibited the invasion and migration of breast carcinoma cells [77].

In addition to solid tumors, abnormal expression of HO- 1 has been linked to oncogenesis and chemo resistance in hematological malignancies. It is reported that $\mathrm{HO}-1$ is constitutively expressed in primary CML cells [43] and acts as a survival molecule in CML cells, as over expression of HO-1 inhibited apoptosis induced by BCR/ ABL tyrosine kinase inhibitor imatinib (STI571). In another study, Mayerhofer et al. [43] showed that inhibition of HO-1 leads to the growth inhibition of imatinib-sensitive as well as imatinb-resistant CML cells [56]. HO-1 is also overexpressed in human primary acute myeloid leukemia (AML) cells where it offers protection from chemotherapyinduced apoptosis [81]. Interestingly, combined inhibition of $\mathrm{HO}-1$ and NF- $\mathrm{KB}$ significantly induced apoptosis in AML cells and thus provided a novel therapeutic approach to treat chemotherapy-resistant forms of AML [82].

In addition, HO-1 inhibition has been reported to have advantageous therapeutic effect on mast cell (MC) neoplasm. HO-1 was found to be overexpressed in neoplastic canine mast cells where it acts as a survival factor [83]. In human mast cells, HO-1 expression was induced by the mastocytosis-related oncoprotein KIT D816V and its inhibition led to the reduced expression of HO-1 and consequently decreased proliferation/survival in neoplastic MCs [44].

\section{Selective inhibition of $\mathrm{HO}-1$ as a new target for anticancer nanotechnology}

As described before, HO-1 plays an important role in cancer progression therefore; selective inhibition of HO-1 has been explored as a novel anticancer therapy. The two main strategies used for selective inhibition of HO-1 are namely, siRNA and metalloporphyrins [16]. However, the greatest impediment in the therapeutic application of these strategies is poor solubility as well as their toxicity and poor delivery to the tumor. By using nanotechnology, various studies have shown targeted delivery of siRNA or protoporphyrins to tumors $[84,85]$. In the next section we discuss the therapeutic implications of both strategies and the attempted use of protoporphyrins for HO-1 inhibition by nanotechnology to address both short comings.

\section{Selective inhibition via siRNA}

Numerous studies have reported the association between decreased expression of HO-1 by siRNA and reduced cell survival in various human neoplasms both in vitro and in vivo. For example, siRNA induced knockdown of HO-1 led to increased apoptosis of cultured colon carcinoma cells, chronic and acute myeloid leukemia cells, lung cancer cells and hepatocarcinoma cells (HCC) [50,39,56,86,41]. In addition, in lung cancer cells, HO-1 siRNA increased the generation of ROS and augmented the cytotoxicity of cisplatin [39]. In pancreatic cancer cells, suppression of HO-1 expression by siRNA resulted in decreased cell proliferation and sensitization of pancreatic cells to oxidative stress and gemcitabine or $\gamma$-radiation [47]. Importantly, HO-1 siRNA reduced growth of orthotopic hepatocellular tumors [41] Alaoui-Jamali et al. [74] demonstrated an inhibition in the therapeutic activity of the HO- 1 by using a small-molecule inhibitor OB-24, which was found to mimic the activity of $\mathrm{HO}-1$ shRNA in prostate cancer cells [74]. OB-24 is a competitive and reversible inhibitor of the HO-1 enzyme which selectively inhibits $\mathrm{HO}-1$ but not $\mathrm{HO}-2$. OB-24 reduced cell proliferation, cell survival and cell invasion in prostate cancer cells in vitro. In addition, it also inhibited prostate tumor growth as well as lymph node and lung metastasis in vivo. Interestingly, OB-24 potentiated the anticancer activity of taxol.

\section{Selective inhibition via proto porphyrin derivatives}

Protoporphyrin (PP) IX is a heme metabolite and its ironexchanged derivatives, such as zinc PPIX (ZnPPIX) and tin PPIX (SnPPIX), have been found to inhibit competitively in vitro and in vivo $\mathrm{HO}$ activity [87]. In contrast, hemin (FePP) and cobalt PPIX (CoPPIX) induce and activate HO-1, while copper PPIX (CuPPIX) does not affect HO-1 activity $[87,88]$. The pharmacological inhibition of HO-1 using protoporphyrins has been reported to exert cytotoxic effects in various cancer cells and thus has potential use for therapeutic treatment of cancer. For example, administration of the HO-1 inhibitor ZnPP via tumor feeding artery significantly suppressed the growth of hepatoma AH136B tumors [37] and this effect was mediated via induction of apoptosis [45]. Similarly, SnPP IX treatment also induced apoptosis in AH136B tumor cells [45]. However, SnPP IX treatment of the rats did not affect the blood flow in the tumor tissue whereas both ZnPPIX and CuPPIX decreased the blood flow to P22 carcinosarcoma tumors in rats [89]. The pretreatment of lung cancer A549 cells with ZnPP produced increased apoptosis incisplatin-treated cells as compared with the cells treated with cisplatin alone which suggests the role of HO-1 in sensitizing lung cancer cells to cisplatin [39]. In addition, simultaneous treatment with $\mathrm{ZnPP}$ and cisplatin synergistically increased reactive oxygen species (ROS) generation and decreased the expression of HO-1 [39]. In colon cancer cells, Zn (II) PPIX exerted potent cytotoxic effect both in vitro and in vivo and this anticancer effect was mediated through a cell cycle arrest, caspase-3 dependent apoptosis induction and increased generation of ROS [90]. Finally, administration of ZnPP significantly inhibited progression of a B-cell leukemia/lymphoma 1 tumor in mice by specially targeting tumor cells and reported HO independent effects of $\mathrm{ZnPP}$ on tumorigenesis [91].However, it is reported that the cytotoxic effect of $\mathrm{ZnPP}$ in rat hepatoma $\mathrm{AH} 136 \mathrm{~B}$ primary cells was reversed by the presence of bilirubin [45]

Although an inhibition of HO-1 by $\mathrm{ZnPP}$ has been widely used for drug development, some conflicting evidence has been reported. Nowis et al. [90] demonstrated that ZnPPIX was unable to restore cisplatin sensitivity in HO-1 over expressing melanoma cells [90]. Also, it didn't potentiate the antitumor effects of cisplatin, doxorubicin or 5-FU in C-26 colon adenocarcinoma; B16F10 melanoma and EMT6 breast adenocarcinoma models. The study warranted more selective and efficient delivery of HO-1 inhibitors to the tumor for combination therapies with chemotherapeutics.

\section{Role of nanotechnology in targeted inhibition of HO-1 in tumors}

HO-1, as evident from the above discussion, is an attractive target for inhibition of tumor progression on the cellular level. However, on tissue level many obstacles have to be overcome before the HO-1 inhibitors can reach its cellular targets at the cytoplasm of tumor cells. First, the HO-1 inhibitor needs to be water soluble so that it can be 
Citation: Yadav B, Greish K (2011) Selective inhibition of hemeoxygenase-1 as a novel therapeutic target for anticancer treatment. J Nanomedic Nanotechnol S4:005. doi:10.4172/2157-7439.S4-005

administered as parenteral therapeutic. Second, the water soluble drug needs to reach the tumor tissues and concentrate their selectively in a therapeutically effective concentration, and finally preferably the drug can retain its therapeutic concentration for extended duration. Unfortunately, neither si RNA, nor metal protoporphyrins satisfy the abovementioned conditions. In this respect, nanotechnology comes into action to render theses promising approaches into potential drug candidates. Tumor tissues are selectively permeable to macromolecules (drugs) of nanosize magnitudes due to their extensive vascular leakage [92]. Specifically, the macromolecules of size exceeding $7 \mathrm{~nm}$, known as nanomedicine have an advantage of evading the tight junction in normal vasculature [92]. More importantly they escape renal clearance for being above the renal excretion threshold, thus they can attain longer circulator life in plasma [93]. As the circulatory half-life and the pharmacological effect are parallel to each other, nanomedicine tends to have prolonged and selective anticancer activity. Thus the chemical conjugation of poor water soluble HO-1 inhibitors into a long chain of high molecular weight polymeric carrier or encapsulating it into the core of a miceller carrier can impose all the advantages needed for clinical applications.

As discussed above, $\mathrm{ZnPP}$ is ideal for selective cancer cell toxicity, as it inhibits HO-1 which is overexpressed by cancer cells and is crucial to their survival. ZnPP has strong phototoxic properties in addition to its capability of radio-sensitization of tumor cells to megavoltage RT [94] (Figure 4). However, the pharmaceutical application of $\mathrm{ZnPP}$ is limited due to its poor water solubility [95]. Therefore, with the help of nanotechnology, a water-soluble micellar form of ZnPP was formulated by conjugating it with polyethylene glycol (PEG) [95]. The PEG-ZnPP micelles have a mean particle size around 180 $\mathrm{nm}$ [96]. This smaller size of micelles offers an advantage of higher vascular permeability at target tumor sites by diffusion mechanisms [97]. Thus, PEG-ZnPP selectively accumulated in tumor tissues utilizing the mechanism called enhanced permeability and retention (EPR) effect and exhibited targeted inhibition of $\mathrm{HO}$ in tumor tissue [98]. In addition, via encapsulation, micelles offer stability and thus improve pharmacokinetics and biodistribution of sparingly soluble anticancer agents [99]. Specifically, the pharmacokinetic profile of PEG-ZnPPIX nanoparticles showed a 40 fold longer plasma residence time compared to free ZnPPIX after intravenous administration [98]. Also, PEGylated ZnPP (PEG-ZnPP) exhibited the desired cytotoxic effects in various cancer cells in vitro and in vivo. For example, PEGZnPP induced oxidative stress, and consequently apoptotic death in colon cancer SW480 cells [98]. Interestingly, PEG-ZnPP preferentially accumulated in solid tumor tissue in a S180 murine model resulting in significant tumor suppression without any side effects [98]. This effect was mediated through targeted suppression of HO-1 and an induction of apoptosis in tumor cells. The similar effect was also observed when PEG-ZnPP was combined with another oxidative chemotherapeutic agent such as PEG-DAO/D-proline (PEG-conjugated D-amino acid oxidase with D proline) [100]. PEG-ZnPP pre-treatment significantly reduced the growth of S180 tumors in mice receiving PEG-DAO/Dproline compared to no PEG-ZnPP pre-treatment. In addition, PEG$\mathrm{ZnPP}$ sensitized colon cancer cells to cytostatic/cytotoxic effects of camptothecin or doxorubicin and suggested the role of HO-1 inhibitor in potentiating the chemotherapeutic response of solid tumors [100].

\section{SMA-ZnPP nanomicelles as a potential anticancer agent}

In spite of having promising anticancer activity in vitro and in vivo, the poor drug ( $\mathrm{ZnPP})$ loading (1.5\% $\mathrm{ZnPP} / \mathrm{PEG}$ w/w ratio) was the critical shortcoming of PEG-ZnPP for its future biological applications
[101]. To overcome this problem, another highly water soluble micellar formulation of $\mathrm{ZnPP}$ was designed by the use of amphiphilic styrenemaleic acid copolymer (SMA), namely SMA-ZnPP [85]. SMA-ZnPP showed higher and more efficient intracellular uptake rate compared to PEG-ZnPP by endocytotic pathway followed by release of free $\mathrm{ZnPP}$ in the presence of membrane components [96]. After its release, $\mathrm{ZnPP}$ is mainly colocalized with $\mathrm{HO}-1$ at endoplasmic reticulum (ER) compartment and inhibits HO-1 activity which leads to higher oxystress and cell death. SMA-ZnPP exist as nanoparticles in aqueous solution and tend to accumulate preferentially at tumor site by the EPR effect therefore it's been used in a variety of ways to induce its anticancer effect [102].

SMA-ZnPP micelles exhibited potent dose dependent HO-1 inhibitory potential as well as cytotoxic effects on KYSE-510 human esophageal cancer cells [101]. Importantly, HO-1 inhibitory potential of native $\mathrm{ZnPP}$ was not altered by its SMA-ZnPP formulation. In animal model, SMA-ZnPP showed potent antitumor effects without any apparent side effects [85]. Kondo et al. [44] reported that both SMA$\mathrm{ZnPP}$ and PEG-ZnPP reduced the growth of mast cell leukemia HMC1 cells in a dose dependent manner [44]. The growth inhibitory effects

\begin{tabular}{|l|l|}
\hline & Reference \\
\hline Cerebral glioblastoma and astrocytomas & (Hara et al., 1996) \\
\hline Oligodendroglioma & (Deininger et al., 2000) \\
\hline lymphosarcoma & (Schacter et al., 1982) \\
\hline Malignant vertical growth melanoma & (Torisu-ltakura et al., 2000) \\
\hline Oral squamous cell carcinoma & $\begin{array}{l}\text { (Chang et al., 2004; Tsuji et al., } \\
\text { 1999) }\end{array}$ \\
\hline Chronic myeloid leukemia & (Mayerhofer et al., 2004) \\
\hline Mast cell leukemia & (Kondo et al., 2007) \\
\hline Renal cell carcinoma & (Goodman et al., 1997) \\
\hline Prostate cancer & (Maines et al., 1996) \\
\hline Hepatoma & (Doi et al., 1999; Sass et al., 2008) \\
\hline Kaposi sarcoma & (Marinissen et al., 2006) \\
\hline Pancreatic cancer & (Berberat et al., 2005) \\
\hline Colorectal cancer & (Becker et al., 2007) \\
\hline Lung cancer & (Hirai et al., 2007) \\
\hline Breast cancer & (Hill et al., 2005) \\
\hline Thyroid carcinoma & (Chen et al., 2004) \\
\hline Gall bladder cancer & (Wang et al., 2010b) \\
\hline
\end{tabular}

Table1: Expression of HO-1 in different types of cancers

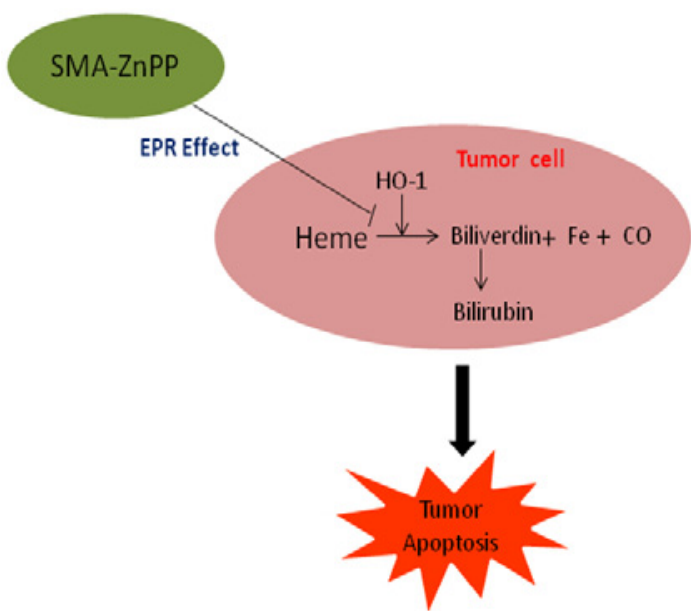

Figure 4: Mechanism of SMA-ZnPP as antitumor agent. 
Citation: Yadav B, Greish K (2011) Selective inhibition of hemeoxygenase-1 as a novel therapeutic target for anticancer treatment. J Nanomedic Nanotechnol S4:005. doi:10.4172/2157-7439.S4-005

of SMA-ZnPP were associated with induction of apoptosis. Moreover, SMA-ZnPP showed powerful cytotoxic activity against primary CML cells obtained from patient's refractory to Gleevec therapy [56]. This response was associated with down-regulation of oncogene BCR-ABL dependent tyrosine kinase activity. Gleixner et al. [103] reported the cytotoxic effect of SMA-ZnPP in a variety of hematopoietic and nonhematopoietic (solid tumors) cells [103].The cell death was associated with induction of apoptosis. In addition, SMA-ZnPP in combination with various targeted drugs or conventional drugs showed synergistic cytotoxicity in myeloid leukemia and various solid tumor cells in vitro [103].

The potential application of the SMA-ZnPP and PEG-ZnPP has also been explored in photodynamic therapy. Iyer et al. [85] reported higher cytotoxic effect of PEG-ZnPP in KYSE-510 human esophageal cancer cell line in the presence of light [85]. Similarly, Regehly et al. [94] reported that in Jurkat cells, SMA-ZnPP causes about five times higher phototoxicity compared to PEG-ZnPP due to higher uptake of ZnPP by tumor cells [94]. Furthermore, in ddY mice bearing S-180 tumors, $12 \mathrm{mg} / \mathrm{kg}$ dose of SMA-ZnPP showed more effective tumor regression when irradiated by a tungsten-xenon light at a luminous intensity of 50,000 LUX for 5 min whereas, utilizing high intensity light (HIL) as a source of irradiation, SMA-ZnPP at 6 or $12 \mathrm{mg} / \mathrm{kg}$ showed marked reduction in tumor growth in DMBA induced mammary cancer model in female SD rats [85]. This effect was attributed to the synergistic effect of oxystress induced killing augmented by in situ free radical generation (in presence of light) by SMA-ZnPP.

\section{Conclusion}

It is now well established that HO-1 is constitutively expressed in various neoplastic cells where it acts as a survival factor and offers cytoprotection to developing tumors. In addition, over expression of HO- 1 promotes angiogenesis and metastasis in tumors and advances resistance against conventional and targeted drugs in various malignancies. Numerous preclinical studies have reported that selective inhibition of HO-1 in tumors leads to reduced tumor growth and increased response to chemotherapy and radiotherapy. Targeted inhibition of HO-1 using nanotechnology has shown promising anticancer effect. The recent advancement in efficient delivery of $\mathrm{HO}-1$ inhibitors to tumor sites presents a new paradigm furthering its future clinical application as anticancer agents.

\section{Acknowledgements}

This work has been supported by Departmental fund No.; (PL. 108403.01.S. LM) to K.G. from department of pharmacology and toxicology, Otago University.

\section{References}

1. Cruse I, Maines MD (1988) Evidence suggesting that the two forms of heme oxygenase are products of different genes. J Biol Chem 263: 3348-3353

2. Maines MD, Trakshel GM, Kutty RK (1986) Characterization of two constitutive forms of rat liver microsomal heme oxygenase. Only one molecular species of the enzyme is inducible. J Biol Chem 261: 411-419

3. Wu L, Wang R (2005) Carbon monoxide: endogenous production, physiological functions, and pharmacological applications. Pharmacol Rev 57: 585-630

4. Serfass L, Burstyn JN (1998). Effect of heme oxygenase inhibitors on soluble guanylyl cyclase activity. Arch Biochem Biophys 359: 8-16

5. ozzelino R, Jeney V, Soares MP (2010) Mechanisms of cell protection by heme oxygenase-1. Annu Rev Pharmacol Toxicol 50: 323-354

6. Wunder C, Potter RF (2003) The heme oxygenase system: its role in liver inflammation. Curr Drug Targets Cardiovasc Haematol Disord 3: 199-208

7. Maines MD (1997) The heme oxygenase system: a regulator of second messenger gases. Annu Rev Pharmacol Toxicol 37: 517-554
8. Maines MD, Ibrahim NG, Kappas A (1977) Solubilization and partial purification of heme oxygenase from rat liver. J Biol Chem 252: 5900-5903

9. Abraham NG, Lin JH, Dunn MW, Schwartzman ML (1987) Presence of heme oxygenase and NADPH cytochrome P-450 (c) reductase in human corneal epithelium. Invest Ophthalmol Vis Sci 28: 1464-1472

10. Gonzalez-Michaca L, Farrugia G, Croatt AJ, Alam J, Nath KA (2004) Heme: a determinant of life and death in renal tubular epithelial cells. Am J Physiol Rena Physiol 286: 370-377

11. Bauer I, Rensing H, Florax A, Ulrich C, Pistorius G, et al. (2003) Expression pattern and regulation of heme oxygenase-1/heat shock protein 32 in human liver cells. Shock 20: 116-122

12. Nishie A, Ono M, Shono T, Fukushi J, Otsubo M, et al. (1999) Macrophage infiltration and heme oxygenase-1 expression correlate with angiogenesis in human gliomas. Clin Cancer Res 5: 1107-1113

13. Pae HO, Oh GS, Choi BM, Chae SC, Chung HT (2003) Differential expressions of heme oxygenase-1 gene in CD25- and CD25+ subsets of human CD4+ T cells. Biochem Biophys Res Commun 306: 701-705

14. Janssen YM, Marsh JP, Absher MP, Gabrielson E, Borm PJ, et al. (1994) Oxidant stress responses in human pleural mesothelial cells exposed to asbestos. Am J Respir Crit Care Med 149: 795-802

15. Keyse SM, Tyrrell RM (1989) Heme oxygenase is the major 32-kDa stress protein induced in human skin fibroblasts by UVA radiation, hydrogen peroxide, and sodium arsenite. Proc Natl Acad Sci U S A 86: 99-103

16. Kinobe RT, Dercho RA, Nakatsu K (2008) Inhibitors of the heme oxygenasecarbon monoxide system: on the doorstep of the clinic? Can J Physiol Pharm 86: $577-599$

17. Motterlini R, Foresti R, Bassi R, Calabrese V, Clark JE, et al. (2000) Endothelia heme oxygenase-1 induction by hypoxia. Modulation by inducible nitric-oxide synthase and S-nitrosothiols. J Biol Chem 275: 13613-13620

18. Tyrrell RM, Applegate LA, Tromvoukis Y (1993) The proximal promoter region of the human heme oxygenase gene contains elements involved in stimulation of transcriptional activity by a variety of agents including oxidants. Carcinogenesis 14: 761-765

19. Fang J, Akaike T, Maeda H (2004a) Antiapoptotic role of heme oxygenase $(\mathrm{HO})$ and the potential of $\mathrm{HO}$ as a target in anticancer treatment. Apoptosis 9 : 27-35

20. Otterbein LE, Choi AM (2000) Heme oxygenase: colors of defense agains cellular stress. Am J Physiol Lung Cell Mol Physiol 279: L1029-1037

21. Ryter SW, Alam J, Choi AM (2006) Heme oxygenase-1/carbon monoxide: from basic science to therapeutic applications. Physiol Rev 86: 583-650

22. Poss KD, Tonegawa S (1997) Reduced stress defense in heme oxygenase 1-deficient cells. Proc Natl Acad Sci U S A 94: 10925-10930

23. Yachie A, Niida Y, Wada T, Igarashi N, Kaneda H, et al. (1999) Oxidative stress causes enhanced endothelial cell injury in human heme oxygenase-1 deficiency. J Clin Invest 103: 129-135

24. Kinobe RT, Dercho RA, Nakatsu K (2008) Inhibitors of the heme oxygenasecarbon monoxide system: on the doorstep of the clinic? Can J Physiol Pharm 86: $577-599$

25. Furuichi M, Yokozuka M, Takemori K, Yamanashi Y, Sakamoto A (2009) The reciprocal relationship between heme oxygenase and nitric oxide synthase in the organs of lipopolysaccharide-treated rodents. Biomed Res 30: 235-243

26. Sasaki T, Yoshida K, Kondo H, Ohmori H, Kuniyasu H (2005) Heme oxygenase-1 accelerates protumoral effects of nitric oxide in cancer cells. Virchows Arch 446: 525-531

27. Wang G, Hamid T, Keith RJ, Zhou G, Partridge CR, et al. (2010a) Cardioprotective and antiapoptotic effects of heme oxygenase-1 in the failing heart. Circulation 121: 1912-1925

28. Dick P, Schillinger M, Minar E, Mlekusch W, Amighi J, et al. (2005) Haem oxygenase-1 genotype and cardiovascular adverse events in patients with peripheral artery disease. Eur J Clin Invest35(12): 731-737

29. Nath KA (2007) Renal response to repeated exposure to endotoxin: implications for acute kidney injury. Kidney Int 71: 477-479

30. Arregui B, Lopez B, Garcia Salom M, Valero F, Navarro C, et al. (2004) 
Citation: Yadav B, Greish K (2011) Selective inhibition of hemeoxygenase-1 as a novel therapeutic target for anticancer treatment. J Nanomedic Nanotechnol S4:005. doi:10.4172/2157-7439.S4-005

Acute renal hemodynamic effects of dimanganese decacarbonyl and cobalt protoporphyrin. Kidney Int 65: 564-574

31. Shimizu H, Takahashi T, Suzuki T, Yamasaki A, Fujiwara T, et al. (2000) Protective effect of heme oxygenase induction in ischemic acute renal failure. Crit Care Med 28: 809-817

32. Soares MP, Lin Y, Anrather J, Csizmadia E, Takigami K, et al. (1998) Expression of heme oxygenase-1 can determine cardiac xenograft survival. Nat Med 4: 1073-1077

33. Neto JS, Nakao A, Kimizuka K, Romanosky AJ, Stolz DB, et al. (2004) Protection of transplant-induced renal ischemia-reperfusion injury with carbon monoxide. Am J Physiol Renal Physiol 287: 979-989

34. Was H, Cichon T, Smolarczyk R, Rudnicka D, Stopa M, et al. (2006) Overexpression of heme oxygenase-1 in murine melanoma: increased proliferation and viability of tumor cells, decreased survival of mice. Am J Pathol 169: 2181-2198

35. Kikuchi A, Yamaya M, Suzuki S, Yasuda H, Kubo H, et al. (2005) Association of susceptibility to the development of lung adenocarcinoma with the heme oxygenase-1 gene promoter polymorphism. Hum Genet 116: 354-360

36. Deininger MH, Meyermann R, Trautmann K, Duffner F, Grote EH, et al. (2000) Heme oxygenase $(\mathrm{HO})-1$ expressing macrophages/microglial cells accumulate during oligodendroglioma progression. Brain Res 882: 1-8

37. Doi K, Akaike T, Fujii S, Tanaka S, Ikebe N, et al. (1999) Induction of haem oxygenase-1 nitric oxide and ischaemia in experimental solid tumours and implications for tumour growth. Br J Cancer 80: 1945-1954

38. Hara E, Takahashi K, Tominaga T, Kumabe T, Kayama T, et al. (1996) Expression of heme oxygenase and inducible nitric oxide synthase mRNA in human brain tumors. Biochem Biophys Res Commun 224: 153-158

39. Kim HR, Kim S, Kim EJ, Park JH, Yang SH, et al. (2008) Suppression of Nrf2 driven heme oxygenase-1 enhances the chemosensitivity of lung cancer A549 cells toward cisplatin. Lung Cancer 60: 47-56

40. Lee TC, Ho IC (1994) Expression of heme oxygenase in arsenic-resistant human lung adenocarcinoma cells. Cancer Res 54: 1660-1664.

41. Sass G, Leukel P, Schmitz V, Raskopf E, Ocker M, Neureiter D, et al. (2008) Inhibition of heme oxygenase 1 expression by small interfering RNA decreases orthotopic tumor growth in livers of mice. Int J Cancer 123: 1269-1277

42. Marinissen MJ, Tanos T, Bolos M, de Sagarra MR, Coso OA, et al. (2006) Inhibition of heme oxygenase-1 interferes with the transforming activity of the Kaposi sarcoma herpesvirus-encoded G protein-coupled receptor. J Biol Chem 28: $11332-11346$

43. Mayerhofer M, Florian S, Krauth MT, Aichberger KJ, Bilban M, et al. (2004) Identification of heme oxygenase-1 as a novel BCR/ABL-dependent survival factor in chronic myeloid leukemia. Cancer Res 64: 3148-3154

44. Kondo R, Gleixner KV, Mayerhofer M, Vales A, Gruze A, et al. (2007) Identification of heat shock protein $32(\mathrm{Hsp32})$ as a novel survival factor and therapeutic target in neoplastic mast cells. Blood 110: 661-669

45. Tanaka S, Akaike T, Fang J, Beppu T, Ogawa M, et al. (2003) Antiapoptotic effect of haem oxygenase-1 induced by nitric oxide in experimental solid tumour. Br J Cancer 88: 902-909

46. Liu ZM, Chen GG, Ng EK, Leung WK, Sung JJ, et al. (2004) Upregulation of heme oxygenase-1 and p21 confers resistance to apoptosis in human gastric cancer cells. Oncogene 23: 503-513

47. Berberat PO, Dambrauskas Z, Gulbinas A, Giese T, Giese N, et al. (2005) Inhibition of heme oxygenase-1 increases responsiveness of pancreatic cancer cells to anticancer treatment. Clin Cancer Res 11: 3790-3798

48. Kocanova S, Buytaert E, Matroule JY, Piette J, Golab J, et al. (2007). Induction of heme-oxygenase 1 requires the p38MAPK and PI3K pathways and suppresses apoptotic cell death following hypericin-mediated photodynamic therapy. Apoptosis 12: 731-741

49. Kuroda H, Takeno M, Murakami S, Miyazawa N, Kaneko T, et al. (2010) Inhibition of heme oxygenase-1 with an epidermal growth factor recepto inhibitor and cisplatin decreases proliferation of lung cancer A549 cells. Lung Cancer 67: 31-36

50. Busserolles J, Megias J, Terencio MC, Alcaraz MJ (2006) Heme oxygenase-1 inhibits apoptosis in Caco-2 cells via activation of Akt pathway. Int J Biochem Cell Biol 38: 1510-1517
51. Chen GG, Liu ZM, Vlantis AC, Tse GM, Leung BC, (2004) Heme oxygenase-1 protects against apoptosis induced by tumor necrosis factor-alpha and cycloheximide in papillary thyroid carcinoma cells. J Cell Biochem 92: 12461256

52. Lin Q, Weis S, Yang G, Weng YH, Helston R, et al. (2007) Heme oxygenase-1 protein localizes to the nucleus and activates transcription factors important in oxidative stress. J Biol Chem 282: 20621-20633

53. Banerjee P, Basu A, Datta D, Gasser M, Waaga-Gasser AM, et al. (2011) The Heme Oxygenase-1 Protein Is Overexpressed in Human Renal Cancer Cells following Activation of the Ras-Raf-ERK Pathway and Mediates Anti-Apoptotic Signal. J Biol Chem 286: 33580-33590

54. Koiso Y, Fujimoto Y, Matsumura D, Nakajima O, Hashimoto $Y$ (1999) Modification by heme oxygenase inhibitor, tin protoporphyrin, of cellular differentiation of human myeloid leukemia K562 cell line. Biol Pharm Bull 22: 439-440

55. Wang J, Zhang M, Zhang L, Cai $H$, Zhou S, et al. (2010b) Correlation of Nrf2, HO-1, and MRP3 in gallbladder cancer and their relationships to clinicopathologic features and survival. J Surg Res 164: 99-105

56. Mayerhofer M, Gleixner KV, Mayerhofer J, Hoermann G, Jaeger E, et al (2008). Targeting of heat shock protein 32 (Hsp32)/heme oxygenase-1 (HO-1) in leukemic cells in chronic myeloid leukemia: a novel approach to overcome resistance against imatinib. Blood $111: 2200$

57. George JF, Braun A, Brusko TM, Joseph R, Bolisetty S, et al. (2008) Suppression by CD4+CD25+ regulatory $T$ cells is dependent on expression of heme oxygenase-1 in antigen-presenting cells. Am J Pathol 173: 154-160

58. Andersen MH, Sorensen RB, Brimnes MK, Svane IM, Becker JC, et al. (2009) Identification of heme oxygenase-1-specific regulatory CD8+ T cells in cance patients. J Clin Invest 119: 2245-2256

59. Tauber S, Jais A, Jeitler M, Haider S, Husa J, et al. (2010) Transcriptome analysis of human cancer reveals a functional role of heme oxygenase-1 in tumor cell adhesion. Mol Cancer 9: 200

60. Vashist YK, Uzungolu G, Kutup A, Gebauer F, Koenig A, et al. (2011). Heme oxygenase-1 germ line GTn promoter polymorphism is an independent prognosticator of tumor recurrence and survival in pancreatic cancer. J Surg Oncol 104: 305-311

61. Miyake M, Ishii M, Kawashima K, Kodama T, Sugano K, et al. (2009) siRNA mediated knockdown of the heme synthesis and degradation pathways: modulation of treatment effect of 5-aminolevulinic acid-based photodynamic therapy in urothelial cancer cell lines. Photochem Photobiol 85: 1020-1027

62. Chang KW, Lee TC, Yeh WI, Chung MY, Liu CJ, et al. (2004) Polymorphism in heme oxygenase-1 (HO-1) promoter is related to the risk of oral squamous cell carcinoma occurring on male areca chewers. Br J Cancer 91: 1551-1555

63. Hu JL, Li ZY, Liu W, Zhang RG, Li GL, et al. (2010) Polymorphism in heme oxygenase-1 (HO-1) promoter and alcohol are related to the risk of esophageal squamous cell carcinoma on Chinese males. Neoplasma 57: 86-92

64. Hong CC, Ambrosone CB, Ahn J, Choi JY, McCullough ML, et al. (2007) Genetic variability in iron-related oxidative stress pathways (Nrf2, NQ01 NOS3, and HO-1), iron intake, and risk of postmenopausal breast cancer. Cancer Epidemiol Biomarkers Prev 16: 1784-1794

65. Lo SS, Lin SC, Wu CW, Chen JH, Yeh WI, et al. (2007) Heme oxygenase-1 gene promoter polymorphism is associated with risk of gastric adenocarcinoma and lymphovascular tumor invasion. Ann Surg Onco I14: 2250-2256

66. Folkman J (1971) Tumor angiogenesis: therapeutic implications. N Engl J Med 285: $1182-1186$

67. Jozkowicz A, Huk I, Nigisch A, Weigel G, Dietrich W, et al. (2003) Heme oxygenase and angiogenic activity of endothelial cells: stimulation by carbon monoxide and inhibition by tin protoporphyrin-IX. Antioxid Redox Signal 5: 155162

68. Silva G, Cunha A, Gregoire IP, Seldon MP, Soares MP (2006) The antiapoptotic effect of heme oxygenase-1 in endothelial cells involves the degradation of p38 alpha MAPK isoform. J Immunol 177: 1894-1903

69. Sunamura M, Duda DG, Ghattas MH, Lozonschi L, Motoi F, et al. (2003) Heme oxygenase-1 accelerates tumor angiogenesis of human pancreatic cancer Angiogenesis 6: 15-24

70. Torisu-Itakura H, Furue M, Kuwano M, Ono M (2000) Co-expression of 
Citation: Yadav B, Greish K (2011) Selective inhibition of hemeoxygenase-1 as a novel therapeutic target for anticancer treatment. J Nanomedic Nanotechnol S4:005. doi:10.4172/2157-7439.S4-005

thymidine phosphorylase and heme oxygenase- 1 in macrophages in human malignant vertical growth melanomas. Jpn J Cancer Res 91: 906-910

71. Miyake M, Fujimoto K, Anai S, Ohnishi S, Kuwada M, et al. (2011) Heme oxygenase-1 promotes angiogenesis in urothelial carcinoma of the urinary bladder. Oncol Rep 25: 653-660

72. Hirai K, Sasahira T, Ohmori H, Fujii K, Kuniyasu H (2007) Inhibition of heme oxygenase- 1 by zinc protoporphyrin IX reduces tumor growth of LL/2 lung cancer in C57B L mice. Int J Cancer120: 500-505

73. Martin MJ, Tanos T, Garcia AB, Martin D, Gutkind JS, et al. (2007) The Galpha12/13 family of heterotrimeric $G$ proteins and the small GTPase RhoA link the Kaposi sarcoma-associated herpes virus $\mathrm{G}$ protein-coupled receptor to heme oxygenase-1 expression and tumorigenesis. J Biol Chem 282: 3451034524

74. Alaoui-Jamali MA, Bismar TA, Gupta A, Szarek WA, Su J, et al. (2009) A nove experimental heme oxygenase-1-targeted therapy for hormone-refractory prostate cancer. Cancer Res $69: 8017-8024$

75. Chong IW, Liu PL, Tsai JR, Wang TH, Hwang JJ (2010) Overexpression Of Heme Oxygenase-1 Gene Increases Cell Metastatic Ability In Non-Small Cell Lung Cancer. Am J of Respir Crit Care Med 181: A2049

76. Gueron G, De Siervi A, Ferrando M, Salierno M, De Luca P, et al. (2009) Critical role of endogenous heme oxygenase 1 as a tuner of the invasive potential of prostate cancer cells. Mol Cancer Res 7: 1745-1755

77. Lin CW, Shen SC, Hou WC, Yang LY, Chen YC (2008) Heme oxygenase-1 inhibits breast cancer invasion via suppressing the expression of matrix metalloproteinase-9. Mol Cancer Ther 7: 1195-1206

78. Becker JC, Fukui H, Imai Y, Sekikawa A, Kimura T, et al. (2007) Colonic expression of heme oxygenase- 1 is associated with a better long-term survival in patients with colorectal cancer. Scand J Gastroenterol 42: 852-858

79. Robertson JM, Lawrence TS, Dworzanin LM, Andrews JC, Walker S, et al. (1993) Treatment of primary hepatobiliary cancers with conformal radiation therapy and regional chemotherapy. J Clin Onco I11: 1286-1293

80. Hill M, Pereira V, Chauveau C, Zagani R, Remy S, Tesson L, et al. (2005) Heme oxygenase- 1 inhibits rat and human breast cancer cell proliferation: mutual cross inhibition with indoleamine 2,3-dioxygenase. FASEB J 19: 1957 1968

81. Miyazaki T, Kirino Y, Takeno M, Samukawa S, Hama M, et al. (2010). Expression of heme oxygenase- 1 in human leukemic cells and its regulation by transcriptional repressor Bach1. Cancer Sci 101: 1409-1416

82. Rushworth SA, Bowles KM, Raninga P, MacEwan DJ (2010) NF-kappaBinhibited acute myeloid leukemia cells are rescued from apoptosis by heme oxygenase-1 induction. Cancer Res 70: 2973-2983

83. Hadzijusufovic E, Rebuzzi L, Gleixner KV, Ferenc V, Peter B, et al. (2008) Targeting of heat-shock protein 32 /heme oxygenase-1 in canine mastocytoma cells is associated with reduced growth and induction of apoptosis. Exp Hematol 36: 1461-1470

84. Davis ME, Zuckerman JE, Choi CH, Seligson D, Tolcher A, et al. (2010) Evidence of RNAi in humans from systemically administered siRNA via targeted nanoparticles. Nature 464: 1067-1070

85. Iyer AK, Greish K, Seki T, Okazaki S, Fang J, et al. (2007b) Polymeric micelles of zinc protoporphyrin for tumor targeted delivery based on EPR effect and singlet oxygen generation. J Drug Target 15: 496-506

86. Rushworth SA, MacEwan DJ (2008) HO-1 underlies resistance of AML cells to TNF-induced apoptosis. Blood 111: 3793-3801

87. Hirai K, Sasahira T, Ohmori H, Fujii K, Kuniyasu H (2007) Inhibition of heme oxygenase- 1 by zinc protoporphyrin IX reduces tumor growth of LL/2 lung cancer in C57BL mice. Int J Cancer 120: 500-505

88. Chow JM, Huang GC, Lin HY, Shen SC, Yang LY, et al. (2008) Cytotoxic effects of metal protoporphyrins in glioblastoma cells: roles of albumin, reactive oxygen species, and heme oxygenase-1. Toxicol Lett 177: 97-107

89. Khelifi AF, Prise VE, Tozer GM (2003) Effects of tin-protoporphyrin IX on blood flow in a rat tumor model. Exp Biol Med 228: 481-485

90. Nowis D, Bugajski M, Winiarska M, Bil J, Szokalska A, Salwa $P$, et al (2008) Zinc protoporphyrin IX, a heme oxygenase-1 inhibitor, demonstrates potent antitumor effects but is unable to potentiate antitumor effects of chemotherapeutics in mice. BMC Cancer 8: 197
91. La P, Fernando AP, Wang Z, Salahudeen A, Yang G, et al. (2009) Zinc protoporphyrin regulates cyclin $\mathrm{D} 1$ expression independent of heme oxygenase inhibition. J Biol Chem 284 : 36302-36311

92. Greish K (2007) Enhanced permeability and retention of macromolecular drugs in solid tumors: a royal gate for targeted anticancer nanomedicines. J Drug Target $15: 457-464$

93. Greish K, Fang J, Inutsuka T, Nagamitsu A, Maeda H (2003) Macromolecula therapeutics: advantages and prospects with special emphasis on solid tumour targeting. Clin Pharmacokinet 42: 1089-1105

94. Regehly M, Greish K, Rancan F, Maeda H, Bohm F, et al. (2007) Water-soluble polymer conjugates of ZnPP for photodynamic tumor therapy. Bioconjug Chem 18: $494-499$

95. Sahoo SK, Sawa T, Fang J, Tanaka S, Miyamoto Y, Akaike T, et al. (2002) Pegylated zinc protoporphyrin: a water-soluble heme oxygenase inhibitor with tumor-targeting capacity. Bioconjug Chem 13:1031-1038

96. Nakamura H, Fang J, Gahininath B, Tsukigawa K, Maeda H (2011) Intracellula uptake and behavior of two types zinc protoporphyrin (ZnPP) micelles, SMAZnPP and PEG-ZnPP as anticancer agents; Unique intracellular disintegration of SMA micelles. J Control Release 155: 367-375

97. Yokoyama M, Satoh A, Sakurai Y, Okano T, Matsumura Y, Kakizoe T, et al (1998) Incorporation of water-insoluble anticancer drug into polymeric micelles and control of their particle size. J Control Release 55: 219-229

98. Fang J, Sawa T, Akaike T, Akuta T, Sahoo SK, et al. (2003) In vivo antitumor activity of pegylated zinc protoporphyrin: targeted inhibition of heme oxygenase in solid tumor. Cancer Res 63: 3567-3574

99. Aliabadi H, Lavasanifar A (2006) Polymeric micelles for drug delivery. Expert opinion on drug delivery 3: 139

100. Fang J, Sawa T, Akaike T, Greish K, Maeda H (2004b) Enhancement of chemotherapeutic response of tumor cells by a heme oxygenase inhibitor pegylated zinc protoporphyrin. Int J Cancer 109: 1-8

101.lyer AK, Greish K, Fang J, Murakami R, Maeda H (2007a) High-loading nanosized micelles of copoly(styrene-maleic acid)-zinc protoporphyrin fo targeted delivery of a potent heme oxygenase inhibitor. Biomaterials 28: 1871 1881

102. Greish K, Nagamitsu A, Fang J, Maeda H (2005) Copoly(styrene-maleic acid)-pirarubicin micelles: high tumor-targeting efficiency with little toxicity. Bioconjug Chem16: 230-236

103. Gleixner KV, Mayerhofer M, Vales A, Gruze A, Hormann G, et al. (2009). Targeting of Hsp32 in solid tumors and leukemias: a novel approach to optimize anticancer therapy. Curr Cancer Drug Targets 9: 675-689

104. Chen GG, Liu ZM, Vlantis AC, Tse GM, Leung BC, et al. (2004) Heme oxygenase-1 protects against apoptosis induced by tumor necrosis factoralpha and cycloheximide in papillary thyroid carcinoma. cells. J Cell Biochem 92: $1246-1256$

105. Goodman Al, Choudhury M, da Silva JL, Schwartzman ML, Abraham NG (1997) Overexpression of the heme oxygenase gene in renal cell carcinoma. Proc Soc Exp Biol Med 214: 54-61

106. Maines MD, Abrahamsson PA (1996) Expression of heme oxygenase-1 (HSP32) in human prostate: normal, hyperplastic, and tumor tissue distribution Urology 47: 727-733

107. Schacter BA, Kurz P (1982) Alterations in hepatic and splenic microsomal electron transport system components, drug metabolism, heme oxygenase activity, and cytochrome P-450 turnover in Murphy-Sturm lymphosarcomabearing rats. Cancer Res 42: 3557-3564

108. Tsuji MH, Yanagawa T, Iwasa S, Tabuchi K, Onizawa K, et al. (1999) Heme oxygenase-1 expression in oral squamous cell carcinoma as involved in lymph node metastasis. Cancer Lett138 : 53-59.

This article was originally published in a special issue, Nanotechnology Targeted Drug Delivery handled by Editor(s). Dr. Sami M. Nazzal, University of Louisiana at Monroe, USA; Dr. Kytai Troung Nguyen, University of Texas at Arlington, USA 